\title{
Evaluation of fractionally distilled Picea abies TMP-turpentine on wood-decaying fungi: in vitro, microcosm and field experiments
}

\section{Joel Ljunggren, et al. [full author details at the end of the article]}

Received: 12 September 2019 / Published online: 3 June 2020

(c) The Author(s) 2020

\begin{abstract}
Synthetic and heavy metal antifungals are frequently used as wood preservatives. However, they exhibit relatively inert biodegradation and toxic properties when leached; this makes their replacement with environmentally degradable yet functional alternatives a key target in the wood protection industry. In this context, distilled fractions of raw thermomechanical pulp turpentine (TMP-T) from Picea abies were assessed for their wood protecting capabilities against wood-decaying fungi. Antifungal bioactivity of fractions and some of their combinations were screened on agar-plates against the brown-rot fungus Coniophora puteana. Addition of TMP-T fractions showed a significant fungal growth rate reduction, while mixtures indicated the presence of synergistic and antagonistic effects. One fraction, obtained after distilling $1 \mathrm{~L}$ TMP-T at $111-177{ }^{\circ} \mathrm{C}$ at 0.5 mbar, showed complete growth inhibition of Antrodia sinuosa, Serpula lacrymans, Serpula himantioides and significant inhibition of Antrodia serialis, Antrodia xantha, Gloeophyllum sepiarium, Heterobasidion parviporum at a concentration of $1000 \mathrm{ppm}$. This fraction was further examined for long- and medium-term effects on wood decay in microcosm soiljar and field experiment, respectively. The known antifungal compounds benzisothiazolinone, 2-octyl-4-isothiazolin-3-one, 3-iodo-2-propynyl $\mathrm{N}$-butylcarbamate and two commercial wood preservatives were used as reference treatments. Commercial preservatives instilled long-term efficacy against $C$. puteana wood decay in a soil-jar microcosm experiment, but no noticeable protection with antifungal compounds or the present treatments was found. However, a moderate effect by the TMP-T fraction from the in vitro assay was observed and the TMP-turpentine distillation residue showed a similar fungal inhibition effect to the most potent commercial treatment after 29 months in the field.
\end{abstract}

Electronic supplementary material The online version of this article (https://doi.org/10.1007/s0022 6-020-01192-3) contains supplementary material, which is available to authorized users. 


\section{Introduction}

Wood-decaying fungi are ecologically important for the release of sequestered carbon and nitrogen (Boddy et al. 2008), and although their ability to degrade wood is of critical importance in nature, they cause detrimental deterioration to wooden structures such as houses, logs and outdoor wood. To enhance the service life of wood products, synthetic preservatives (Råberg and Hafrén 2008), waxes (Brischke and Melcher 2015; Liu et al. 2018), linseed oil (Humar and Lesar 2013) and other essential oils (Hyvönen et al. 2006; Medeiros et al. 2016; Wang et al. 2005) have frequently been used as topical or impregnated protective measures against wood-decaying fungi (Humar and Lesar 2013). With increasingly pervasive public environmental concerns, products from nature have in the last decades experienced a renaissance as wood protective measures as well as providing companies with the necessary goodwill incentive to look for more eco-friendly replacements (Sen 2001). As an alternative to synthetic wood preservatives, products from trees carry a natural and latent potential as fungicide sources for inhibiting wood-decaying fungi (Chong et al. 2009; Schultz and Nicholas 2000; Valette et al. 2017).

Trees co-evolved during millions of years with their degraders, a process that honed and primed their natural defences (Stokland 2012). Apart from the defensive bark barrier, trees produce resin-type compounds, phytoalexins, as a response to fungal attack (Kuć and Rush 1985). Phytoalexins are a diverse group of natural compounds that include alkaloids, glycosteroids and terpenoids. An essential oil that contains many of the terpenoids present when trees protect themselves is the essential oil from spruce (Arnerup et al. 2011). In the thermomechanical pulping process, wood essential oil is obtained in large quantities as a by-product by hydrodistillation of wood chips. The resulting essential oil is hereafter referred to as thermomechanical pulp turpentine (TMP-T). Essential oils from various sources have previously shown inhibitory or biocidal effects on an array of different organisms: parasites (Izumi et al. 2012), bacteria (Miladinovic et al. 2012), moulds (Akgül and Kivanç 1989), insects (Boulogne et al. 2012) and filamentous fungi (Inouye et al. 1998). Additionally, they are generally considered safe for humans and have found long-term use in drug formulations, food preservation and as flavouring agents (Bakkali et al. 2008; Smith et al. 2005). In general, terpenes consist of isoprene units where a monoterpene involves a linear or cyclic combination of two isoprene units. The main constituents of the TMP-T used in this study have been characterised previously as the bicyclic monoterpene isomers $\alpha$ - and $\beta$-pinene and, to a lesser extent, terpenoids, sesquiterpenes, higher terpenes, phenols, fatty and resinous acids (Lindmark-Henriksson 2003).

Indigenous wood extractives as wood preservatives in naturally durable wood species against some wood-decaying fungi have been shown to elicit antifungal activities previously (Kirker et al. 2013). Efficient and comprehensive use of any natural by-product such as TMP-T is vital for greener and circular economies. However, the antifungal effect of TMP-T fractions from Norway spruce has not been established neither in vitro nor in outdoor applications. The aim of the 
present study was to screen whether antifungal activity of turpentine could be increased by separating its constituents through fractional vacuum distillation.

\section{Materials and methods}

\section{Chemicals}

A range of different chemicals was tested for their antifungal activity. TMP-turpentine was obtained from the thermomechanical pulp and paper mill SCA Ortviken (Sundsvall, Sweden). The turpentine obtained from SCA Ortviken is exclusively extracted from Norway spruce. TMP-T (1 L) was previously divided by vacuum distillation into 23 fractions (Online Resource 1), and the fractional constituents are summarised in Table 1. An ether extract from SCA Ortviken debarking water containing the antioxidants piceatannol, resveratrol and isorhapontigenin was included as it has exhibited complete inhibition of A. xantha, G. separium and A. serialis at a concentration of 676 ppm (Hedenström et al. 2016). Benzisothiazolinone (BIT; SKU: 561487; CAS number: 2634-33-5), 2-octyl-4-isothiazolin-3-one (OIT; SKU: 46078; CAS number: 26530-20-1), tebuconazole (TA; SKU: 32013; CAS number: 107534-96-3) and 3-iodo-2-propynyl $N$-butylcarbamate (IPBC; SKU: 521949; CAS number: 55406-53-6) were purchased from Sigma-Aldrich. TA and OIT were of PESTANAL analytical standard grade. Beckers impregnation oil (Beckers Färg, Sweden) and Yunik Cronol were purchased from the local hardware store. Both Beckers impregnation oil and Yunik Cronol are sold as wood preservatives for untreated wood, and both contain IPBC. For a paint to be considered for ecolabelling according to the European Commission article 2014/312/EU, the maximum concentration of IPBC is $110 \mathrm{ppm}$. All other commercial wood preservative substances were used in their molar equivalents.

\section{Fungal species and strains}

Eight species of wood-decaying fungi associated with damage of wood structures, stored timber or living trees were selected: Antrodia serialis, Antrodia sinuosa, Antrodia xantha, Coniophora puteana, Gloeophyllum sepiarium, Heterobasidion parviporum, Serpula himantioides and Serpula lacrymans. The Antrodia species are brown-rot fungi that primarily attack construction timber and fresh wood close to the ground (Schmidt 2006; Schmidt and Moreth 1995). Coniophora puteana causes brown-rot both indoors and outdoors in stored wood and constructions. It is considered one of the most destructive fungi in temperate and boreal areas (Kleist and Schmitt 2001). Gloeophyllum sepiarium is a brown-rot fungus attacking stored timber and finished timber subjected to moisture, such as poles, fences, sleepers and window constructions (Schmidt 2006). Heterobasidion parviporum is a white-rot fungus causing root and butt rot in living Norway spruce and is one of the economically most damaging plant diseases in northern temperate regions (Asiegbu et al. 2005). It colonises living trees by infecting adjacent stumps and is typically 


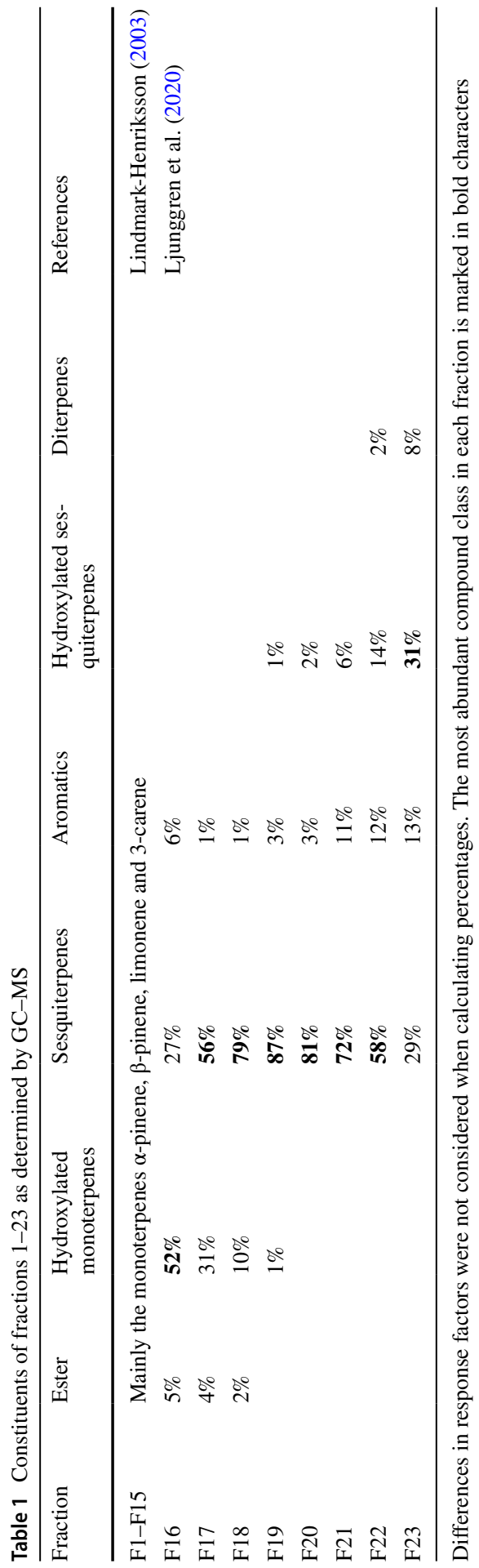


a problem after pre-commercial thinning operations. Serpula himantioides is a brown-rot fungus attacking outdoor structural timber and is only occasionally found indoors, whereas S. lacrymans is considered as an extremely destructive fungus in sheltered indoor conditions in temperate and southern boreal regions (Schmidt 2006).

To provide the most natural and non-laboratory domesticated fungal specimens, saproxylic fungi were isolated from their natural habitats. All species except for $S$. lacrymans were isolated from fruiting bodies collected from conifer logs in forest stands close to Sundsvall, central Sweden. The S. lacrymans strain originated from an infected house in southern Norway. All fungi samples were isolated in the same manner as follows: small pieces $(\sim 1-2 \mathrm{~mm})$ of the basidiocarp were inoculated in a sterile bench onto selective Hagem agar supplemented with: benomyl (4 mg), thiabendazole $(125 \mathrm{mg})$, penicillin $(30 \mathrm{mg})$, streptomycin $(30 \mathrm{mg})$ and tetracycline $(30 \mathrm{mg}) \mathrm{L}^{-1}$ to inhibit growth of bacteria, ascomycetes, zygomycetes and other unwanted specimens. Growing mycelium from each species was retrieved from the selective agar-plates and transferred to another plate with selective medium. Thereafter, the fungal isolates were inoculated on standard Hagem agar. All strains were added to Mid Sweden University's saproxylic fungal collection. Species identities of isolated strains were assigned based on their fruiting body as well as studying the texture and colour of the aerial mycelium (Stalpers 1978). In some cases, samples were also taken for microscopic identification (Ryvarden and Melo 2014). In addition, all strains were sequenced using the internal transcribed spacer (ITS) region and their respective contigs were deposited into GenBank with the following accession numbers: A. serialis (805 bp, KC491853.1), A. sinuosa (775 bp, KC491849.1), A. xantha (791 bp, KC491850.1) C. puteana (864 bp KC491854.1), G. sepiarium (634 bp, KC491852.1), H. annosum sensu lato (694 bp, KC491851.1), S. himantioides (715 bp, KC491848.1) and S. lacrymans (708 bp, KC491847.1). For details regarding PCR and sequencing, see Online Resource 2.

\section{Agar-plate test}

Initially, a binary assay was applied to determine the most effective half of fractioned TMP-T. Raw TMP-T (5 mL) was distilled, and the first fraction was collected from the lowest boiling point to $200-240{ }^{\circ} \mathrm{C}$ at atmospheric pressure. Based on the table in Online Resource 2, the distilled fraction was chosen to represent fractions 1-15, while the remaining turpentine residue represents fractions 16-23 including the previously distilled residue. The wood-decaying fungus $C$. puteana was used as a model species because of its fast-growing properties, symmetrical growth on agar, worldwide distribution and frequent association with undesired brown-rot decay of buildings and stored wood.

Agar-plate tests were performed as previously described (Hedenström et al. 2016) with minor modifications. The present model specimen was grown on $9 \mathrm{~cm}$ Hagem agar-plates (Palmer 1971) supplemented with raw TMP-T and TMP-T fractions in triplicates before autoclaving the nutrient medium for $20 \mathrm{~min}$ at $120{ }^{\circ} \mathrm{C}$. Even though turpentine containing samples were stirred prior to pouring the plates, 
a slight film formation, which may cause the concentration perceived by the fungus to be higher than anticipated, was observed at agar surfaces. Addition of an emulsifier might have homogenised samples further; however, fungi-emulsifier interactions may be species-dependent, used as a nutrient source and exhibit differential effects depending on the emulsifier used. For the interested reader, an in-depth review regarding mainly single-cell microorganisms was recently published (Van de Vel et al. 2019). A $3 \mathrm{~mm}$ plug was put face up onto the supplemented plates' centre from an already established culture of $C$. puteana (7 days). The inoculum plug was taken from actively growing hyphae at the perimeter of the fungus. The diameter of the mycelia was measured in millimetres with a ruler after the third day following inoculation. Coniophora puteana grown on Hagem agar without supplement of TMP-T was used as a positive control.

After the binary assay, fractions 16-23 were selected for further inquiries into their fungal growth inhibitory potential. Note that when TMP-T is fractioned further, the individual fractions will contain a higher concentration of their respective components compared to raw TMP-T. Hence, the initial concentration determined in the preliminary experiment above was reassessed and thus lowered. Concentrations $1000 \mathrm{ppm}$ and $5000 \mathrm{ppm}$ were tested at two different times with separate control samples. Apart from testing fractions 16-23 individually, groups of fractions were combined to assess any synergistic and antagonistic effects. Scardavi (1966) defined interactions as additive, and the effect is compounded when two or more constituents are added together: synergistic, more than the sum of their parts; or antagonistic, less than the sum of their parts. Synergistic effects are highly beneficial since they permit a lower dosage of each amendment than if they were used separately (Tallarida 2001). It should be noted that additive effects were not tested as mixing fractions, while keeping the same total concentration as individual fractions is a zero-sum approach. The groups were mixed in identical proportions as follows: $\mathrm{G} 1=$ Fraction 16, 17, 18, 19; G2 = 20, 21, 22, 23; G3 = 18, 19, 20, 21, and G4=16, $17,22,23$. Dose-response linearity was estimated by dividing mean growth rate measurements at $1000 \mathrm{ppm}$ by five and comparing with corresponding values at 5000 ppm. Likewise, for expected linear growth estimation of groups G1-G4, a linear combination of the individual fractions responses was made.

\section{Wood treatments}

To test antifungal effects of these TMP-T extracts in comparison with other wood preservatives, decay tests were performed on wood pieces. The treatments included one TMP-T fraction, an ether extract from debarking water and four commonly used active ingredients of commercial wood preservatives dissolved in ethyl acetate and two wood impregnation oils. As some TMP-T residue constituents (Lindmark-Henriksson 2003) are known to exhibit antifungal effects on Trametes versicolor and Irpex lacteus (Eberhardt et al. 1994; Kusumoto et al. 2014), the TMP-T distillation residue was also investigated. Due to its relatively high viscosity, the residue was diluted with ethyl acetate (3:1). Two types of controls were used, the first control group was untreated wood and the second control group was painted using ethyl 
acetate without supplement to evaluate whether residual ethyl acetate affected fungal growth. Ethyl acetate was used as some of the fractions did not completely dissolve in hexane. Four active components of commercial wood preserving paints were dissolved in ethyl acetate to a concentration of $0.356 \mathrm{mM}$ for IPBC, BIT, OIT and TA. TMP-T fraction 23 was used at $1000 \mathrm{ppm}$ and $7500 \mathrm{ppm}$. To enable a rough comparison with TMP-T fraction 23, the concentration of the ether extract was used at 1000 ppm. Beckers wood impregnation oil and Yunik Cronol were used as supplied in their formulated form.

A wooden board (Picea abies) was purchased at the local hardware store and cut into rectangular $75 \times 30 \times 21 \mathrm{~mm}$ blocks with a volume of $4.4 \times 10^{-5} \mathrm{~m}^{3}$. Mean density of the board was determined as $485 \mathrm{~kg} \mathrm{~m}^{-3}$ using the water displacement method after conditioning at $20{ }^{\circ} \mathrm{C}$ and $70 \%$ relative humidity until constant weight. Wood pieces were sanded with increasingly fine grain size until a fine polish was achieved. Ring widths were imaged with a scanner and imported into the image analysing software WINDENDRO (version 2014) for standard dendrochronological ring width assessment (Speer 2010). The average ring width over four samples and twenty rings was determined as $2.35 \mathrm{~mm}$. To reduce evaporation of semi-highboiling fractions at the end of experiment, a gentler temperature than the standard temperature of $103{ }^{\circ} \mathrm{C}$ was chosen. Oven dry weight (ODW) was recorded to the nearest $0.001 \mathrm{~g}$ after drying at $65{ }^{\circ} \mathrm{C}$ for 3 days with an average dry weight of 18.8 grams. After drying, wood pieces were singly streaked on all sides using a paintbrush and each treatment was executed in triplicate. After application of treatments, wood pieces were left to dry overnight on a ventilation bench at room temperature. Negative weights after application and drying were considered as equal to zero. The weight taken after the application of paint was subsequently used to determine the weight change at the end of the experiment.

Furthermore, based on the weights after treatment (WAT), it was assumed that wood pieces treated with ethyl acetate including the present compounds of interest absorbed aqueous vapour while film-forming commercial treatments and the distillation residue completely excluded water vapour absorption from the time of application and drying until gravimetric measurements. Thus, the mean of ethyl acetate treated wood samples was subtracted from the other treatments that used ethyl acetate as a solvent and no corrections were made for the distillation residue and the commercial treatments.

\section{Microcosm wood decay tests on soil}

A laboratory soil contact microcosm system was devised to imitate on-site degradation over a long period of time. The substrate used was a mixture of mineral soil, sand and potting soil in a 3:2:1 ratio with the addition of water. This soil composition is used as plant nursery soil, and due to the rich amount of nutrients and airiness, it facilitates hyphal growth and soil penetration, respectively. Mineral soil from one of the field treatment sites: Tunadal, 62 $25^{\prime} 05.1^{\prime \prime} \mathrm{N} 17^{\circ} 22^{\prime} 35.5^{\prime \prime} \mathrm{E}$, was dried at $105^{\circ} \mathrm{C}$ in the oven with medium ventilation. After sieving the soil with a $2 \mathrm{~mm}$ sieve, dried soil $(3 \mathrm{~L})$, sand $(1.5 \mathrm{~L})$, potting soil from Hasselfors Garden AB 
(Örebro, Sweden) (1 L) and distilled water (1.4 L) were mixed and homogenised. After equilibrating 1:1 soil mixture and distilled water $(\mathrm{w} / \mathrm{v})$ at room temperature, the $\mathrm{pH}$ of the mixture was measured with a 744 Metrohm $\mathrm{pH}$-meter as 6.5. Glass jars $(0.5 \mathrm{~L})$ with soil mixture were sterilised by autoclaving at $120{ }^{\circ} \mathrm{C}$ for $20 \mathrm{~min}$ before inoculated with a $5 \mathrm{~mm}$ diameter agar plug with one strain of $C$. puteana and subsequently sealed with parafilm. To allow the fungus time to start foraging, wood pieces were added to the jars after 4 days. To speed up fungal colonisation, an additional $5 \mathrm{~mm}$ plug was added beside the wood piece. In addition, sterile water $(2 \mathrm{~mL})$ was added to improve the moisture conditions for the fungus. After 29 months in room temperature (approx. $20^{\circ} \mathrm{C}$ ), the experiment was ended, and wood pieces containing fungal biomass were oven dried and gravimetrically measured as previously described.

\section{Field wood decay tests}

Treatments and wood pieces were prepared as described for the microcosm paragraph. The experiment was conducted at three different sites to accommodate different wood-decaying microorganisms. The assay included thirteen treatments including controls and seven replicates each, for a total of 273 individual trials. Wood pieces were placed at random positions with a distance of $50 \times 50 \mathrm{~cm}$, within a total area of $600 \times 300 \mathrm{~cm}$ at three different locations: Bergsåker, 62 $24^{\prime} 41^{\prime \prime} \mathrm{N}$ $17^{\circ} 13^{\prime} 45^{\prime \prime} \mathrm{E}$, which is a plane grassland area on sandy-loam soil with sparsely placed deciduous trees, Tunadal, 62 $25^{\prime} 05.1^{\prime \prime} \mathrm{N} 17^{\circ} 22^{\prime} 35.5^{\prime \prime} \mathrm{E}$, which is a sloping cultivated forest area facing east with Norway spruce, birch and rowan trees growing on mossy soil, and Nedansjö, 62 $22^{\prime} 41.2^{\prime \prime} \mathrm{N} 16^{\circ} 49^{\prime} 18.5^{\prime \prime} \mathrm{E}$, which is a sloping grassland area with surrounding bush wood facing east with a small stream close by. Areas suitable for growth of wood-decaying fungi in terms of moisture content and temperature were selected. After leaving the painted wood pieces in direct ground contact (use class 4 according to EN 335 2013) for 29 months, they were oven dried and gently brushed to remove mud, moss and surface growing mycelia. Painting the wood pieces rather than impregnating them according to, for example, EN 252 (2015), was performed to accelerate wood decay and decrease experimental time. The ratio between final oven dry weight and oven dry weight before field experiment was used as a measure of biodegradation by wood-decaying fungi or other organisms.

\section{Statistical analysis}

Analyses of variance (ANOVA) were conducted on growth rates and the percentage weight loss data after arcsine square-root transformation in MATLAB 2018b (MathWorks). Post hoc analysis of treatment means for microcosm and in vivo experiments were compared using Tukey-Kramer's honest significance test with a significance level of $p<0.05$.

Corrected effect sizes (Hedges' $g$ ) and their corresponding confidence intervals were calculated as: 


$$
g=\frac{\bar{x}_{c}-\bar{x}_{i}}{\sqrt{\frac{s_{i}^{2}\left(n_{i}-1\right)+s_{c}^{2}\left(n_{c}-1\right)}{d f}} \frac{\text { def }}{=} s_{\text {pool }}}\left(1-\frac{3}{4\left(n_{1}+n_{2}\right)-9}\right) \pm t(d f)_{(1-\alpha)} \sqrt{\frac{\left(n_{i}+n_{c}\right)}{n_{i} n_{c}}+\frac{\left(s_{\text {pool }}\right)^{2}}{2\left(n_{i}+n_{c}\right)}}
$$

where $d f=$ degrees of freedom as $n_{i}+n_{c}-2 ; \bar{x}_{c}=$ mean of control; $\bar{x}_{i}=$ mean of treatment; $s=$ standard deviation; $n=$ number of replicates.

\section{Results and discussion}

The turpentine made by distilling Picea abies wood chips from thermomechanical pulp production is a complex by-product that consists of $100+$ compounds present at different concentrations and with varying effect on fungal growth (Ljunggren et al. 2020). Distilled fractions of turpentine were evaluated for their efficacy against wood-decaying fungi, and differential fungal growth response reveals antifungal relevance according to boiling point and applicability.

\section{Efficacy of fractioned turpentine on agar-plates}

A one-way ANOVA between compounded fractions 1-15, 16-23 including residue, raw turpentine and control was performed as a rapid approach to assess differential treatment effect (Fig. 1a). A significant treatment effect at the $p<0.05$ level $\left[F_{3,8}=234.74, p \ll 0.05\right]$ followed by Tukey's post hoc analysis showed that growth of $C$. puteana was reduced by both turpentine fractions at $10,000 \mathrm{ppm}$. The highest reduction was noted for the compounded fraction 16-23. The relatively low response of the compounded fraction 1-15 is in contrast to the commonly reported notion that biological activity of essential oils is primarily caused by their major components (Bakkali et al. 2008; Burt 2004; Lopez-Reyes et al. 2013; Shukla et al. 2012).

The main constituents of fraction 1-15, and similarly raw turpentine, are 62/38 ( \pm )- $\alpha$-pinene) and 3/97 ( \pm )- $\beta$-pinene (Groth 1958), limonene and other volatile monoterpenes (Lindmark-Henriksson 2003). As a major component in Pinus rigida essential oil, $\alpha$-pinene has been proposed as a potentially active component against mould fungi (Salem et al. 2016). Moreover, Rivas da Silva et al. (2012) showed that $(+)-\alpha$-pinene and (+)- $\beta$-pinene have a microbicidal effect against the yeasts Candida albicans and Cryptococcus neoformans, the mould fungus Rhizopus oryzae and methicillin-resistant Staphylococcus aureus bacterium with activities in the range of $117-4150 \mathrm{ppm}$. Their corresponding (-) enantiomers did not show any activity up to $20,000 \mathrm{ppm}$. Due to the lower effect observed for these fractions, it was shown that major TMP-T components were less active than minor components when targeting the wood-decaying fungi $C$. puteana. A likely explanation may be that wooddecaying fungi are more adapted to $(+)$ - $\alpha$-pinene degradation or disposal than yeasts and moulds. However, the fact that antagonistic effects between the monoterpenes limonene and $\alpha$-pinene have been suggested (Maree et al. 2014) complicates any decisive conclusion regarding individual antifungal efficacy. 
(a)



(b) 18

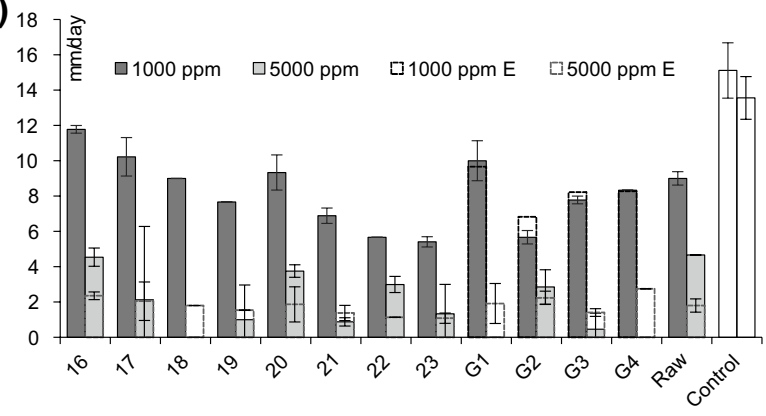

(c)

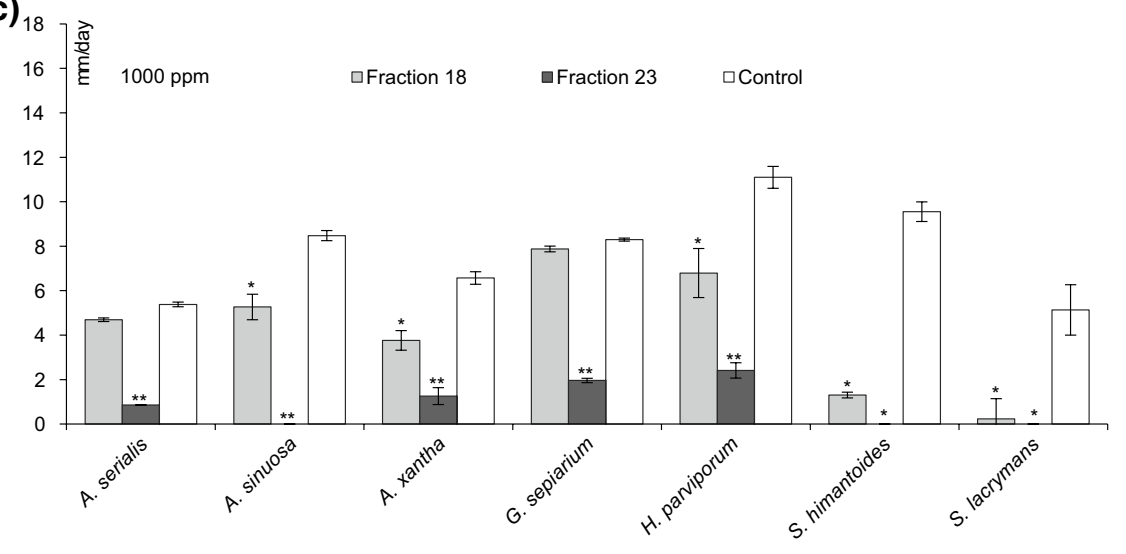

Fig. 1 In vitro efficacy of turpentine fractions. a Effect of compounded fractions (1-15 and 16-23 including distillation residue) from the table in Online Resource 1 and raw turpentine on C. puteana growth rate. b Each fraction from 16 to 23 was examined separately at concentrations 5000 and $1000 \mathrm{ppm}$. Dashed bars, $1000 \mathrm{ppm} \mathrm{E}$ and $5000 \mathrm{ppm}$ E, represent expected values when a linear dose-response is assumed. Groups of fractions are shown as G1-G4 where G1=Fraction 16, 17, 18, 19; $\mathrm{G} 2=20,21,22,23 ; \mathrm{G} 3=18,19,20,21$ and $\mathrm{G} 4=16,17,22,23$ in equal proportions. The control to the left and the right corresponds to the experiment performed at a concentration of $1000 \mathrm{ppm}$ and 5000 ppm, respectively. c Fractions 18 and 23 were further tested against seven saproxylic fungi at a concentration of $1000 \mathrm{ppm}$. *Significant differences as $p<0.05$ and ** differences between fractions. Column heights and error bars: column heights show the average fungal growth rate in mm day ${ }^{-1}$ from triplicate experiments. All error bars represent $95 \%$ confidence intervals, and missing error bars are due to zero differences between replicates

Moreover, monoterpenes are effective against Candida albicans (Martínez et al. 2014), Saccharomyces cerevisiae (Belletti et al. 2004), but also wood decayers such as Trametes hirsuta, Schizophyllum commune and Pycnoporus sanguineus (Zhang et al. 2016). However, their use as natural bioactive agents is primarily restricted by their volatile nature, where the effect may be lost shortly after treatment. The larger cousins of monoterpenes, i.e. sesquiterpenes, diterpenes and their terpenoid derivatives, are less volatile, and their relatively lower vapour pressures are better suited for long-term usage. The present findings indicate that these substances are more capable of inhibiting growth of wooddecaying fungi. This may imply that Norway spruce produces compounds against 
saproxylic fungi that are supposed to protect the tree for an extended period. An added benefit of less volatile compounds is that they are not as likely to cause adverse effects in human respiratory airways during application. Applying TMP-T fractions with lower volatility will thus increase the protective effect while lowering volatile toxicity.

It has been suggested that fractionation of complex natural product extracts, to isolate individual active compounds, is often challenged by a loss of activity due to loss of holistic synergism (Inui et al. 2012). This could explain the phenomenon that fractions 1-15 were less effective when compared to raw TMP-T. However, it was shown that latter fractions increase fungal growth inhibiting capability in contrast with their raw turpentine source at the same concentration. A probable explanation is that crude fractionation by distillation ensures an increased concentration of components compared to raw TMP-T and does not entirely isolate individual compounds. Thus, some measure of leaving potentially beneficial synergistic effects is still present.

Based on the preceding results, fractions 16-23, fraction blends, raw turpentine and standard control (no addition of turpentine) were tested at concentrations of 1000 and 5000 ppm (Fig. 1b). A two-way interaction ANOVA [Fractions: $F_{13,56}=50.09, p \ll 0.05$; Concentration: $F_{1,56}=782.53, p \ll 0.05$; Fraction $\times$ Concentration: $F_{13,56}=10.37, p \ll 0.05$ ] followed by Tukey-Kramer HSD showed that all treatments were effective except for fraction 16. At a concentration of 1000 ppm per fraction, a trend of increasing inhibition from fraction 16 to fraction 19 was interrupted by a decrease in effectiveness by fraction 20 (Fig. 1b). Even at the higher concentration of $5000 \mathrm{ppm}$, fraction 20 deviated from the trend of increased inhibition as fractions shifted towards less volatile components. This may be attributed to the observation that fungi produce hydrocarbon sesquiterpenes and they should be naturally habituated towards them, but only a few fungal oxygenated sesquiterpenes have been reported (Kramer and Abraham 2012). This is also congruent with the steady state of hydrocarbon sesquiterpenes after Norway spruce defence induction by methyl jasmonate (Martin et al. 2002). Based on the knowledge of the constituents of the fractions (Ljunggren et al. 2020), the current results also support the notion that hydroxylated sesquiterpenes from Norway spruce exhibit more potent antifungal capabilities than their hydrocarbon counterparts.

An additional possibility for the lower activity of fraction 20 could be that the inhibition is curbed by the increased presence of substances with growth-inducing effects. Apart from its difference with other fractions, fraction 20 also exhibited nonlinearity at both low and high concentrations. In addition, nonlinear responses to the applied concentration were observed for TMP-T fractions 16, 18, 20 and 22. Figure $1 \mathrm{~b}$ reveals potentially synergistic effects for groups G1 and G4. Additionally, Fig. 1b shows that fraction 23 had the highest effect on $C$. puteana growth rate, i.e. the lowest mean at $1000 \mathrm{ppm}$, while fraction 18 showed complete $C$. puteana growth inhibition at $5000 \mathrm{ppm}$. The appearance of nonlinear effects at higher dosages may be caused by an increase in antagonistic or synergistic compounds, and thus, higher-order interactions may have played a more prominent role here. These results are in line with the findings of Kamo and Yokomizo (2015), who showed that nonlinear effects increase as the chemical concentration goes up. 
Building on the interaction ANOVA results, the growth-reducing potentials of fractions 18 and 23 were examined when faced with a panel of different wooddecaying fungi (Fig. 1c). Fraction 23 caused complete growth inhibition of A. sinu$o s a$, S. himantioides and $S$. lacrymans and substantial inhibition of the other species [Fractions: $F_{13,56}=50.09, p \ll 0.05$; Concentration: $F_{1,56}=782.53, p \ll 0.05$; Fraction $\times$ Concentration: $\left.F_{13,56}=10.37, p \ll 0.05\right]$. The two treatments were also significantly different from each other, except for the Serpula species. The two fungi from the genus Serpula showed a higher susceptibility to both TMP-T fractions than the other tested fungi, potentially signifying their inability to infest standing trees with an active defence mechanism.

Overall, all fractions and raw TMP-T were found to have a negative influence on fungal growth, and the fraction corresponding to the highest boiling point was found to have the highest potential as a fungal growth suppressor and fungicidal medium at a concentration of $1000 \mathrm{ppm}$. This concentration is less than the lowest concentration with no growth of Alternaria alternata, Fusarium subglutinans, Chaetomium globosum, Aspergillus niger and Trichoderma viride when treated with raw essential oil from Pinus rigida at concentration levels 2500-5000 ppm (Salem et al. 2016). In comparison, a decrease in growth rate after fractionation and complete growth inhibition of three wood-decaying fungi at a concentration of $1000 \mathrm{ppm}$ were observed. Moreover, the treatment at $1000 \mathrm{ppm}$ was likely biocidal as no-growth specimens (Fig. 1c) were unable to start growing when transferred to fresh media after two weeks from experimental onset. These findings support the use of fractional distillation or other separation techniques as a way to increase antifungal efficacy of turpentine.

\section{Microcosm}

Based on results from the present growth activity assay, fraction 23 was selected as the best candidate for general fungal inhibition. A microcosm soil experiment was set up to examine its long-term treatment effects. It was hypothesised that treating $P$. abies wood pieces with waste products from the paper industry, an ether extract of debarking water and TMP-T fractions, would return some of the wood's natural preservatives and increase its resistance against fungal decay. Given that $C$. puteana was supplied with a limited amount of nutrients and water, it was likewise expected that any change in the degree of decay would be counterbalanced by an initial efficacy of the antifungal treatments and that the experiment would naturally conclude when water levels approached zero due to natural evaporation. Furthermore, loss of efficacy would not be influenced by rain cycles and thus avoid leaching and loss of effective substances, apart from biodegradation by C. puteana.

Results of the microcosm in vitro treatment tests against the wood-decaying fungus $C$. puteana are listed in Table 2. Mean percentage retention mass increase (see WAT in Table 2) showed additive mass changes for the distillation residue, Beckers impregnation oil and Yunik Cronol after treatment application. A few weeks after inoculation, no fungal growth was seen in jars with Beckers impregnation oil and it was determined that the inoculum did not survive. Supposedly, the compounds 


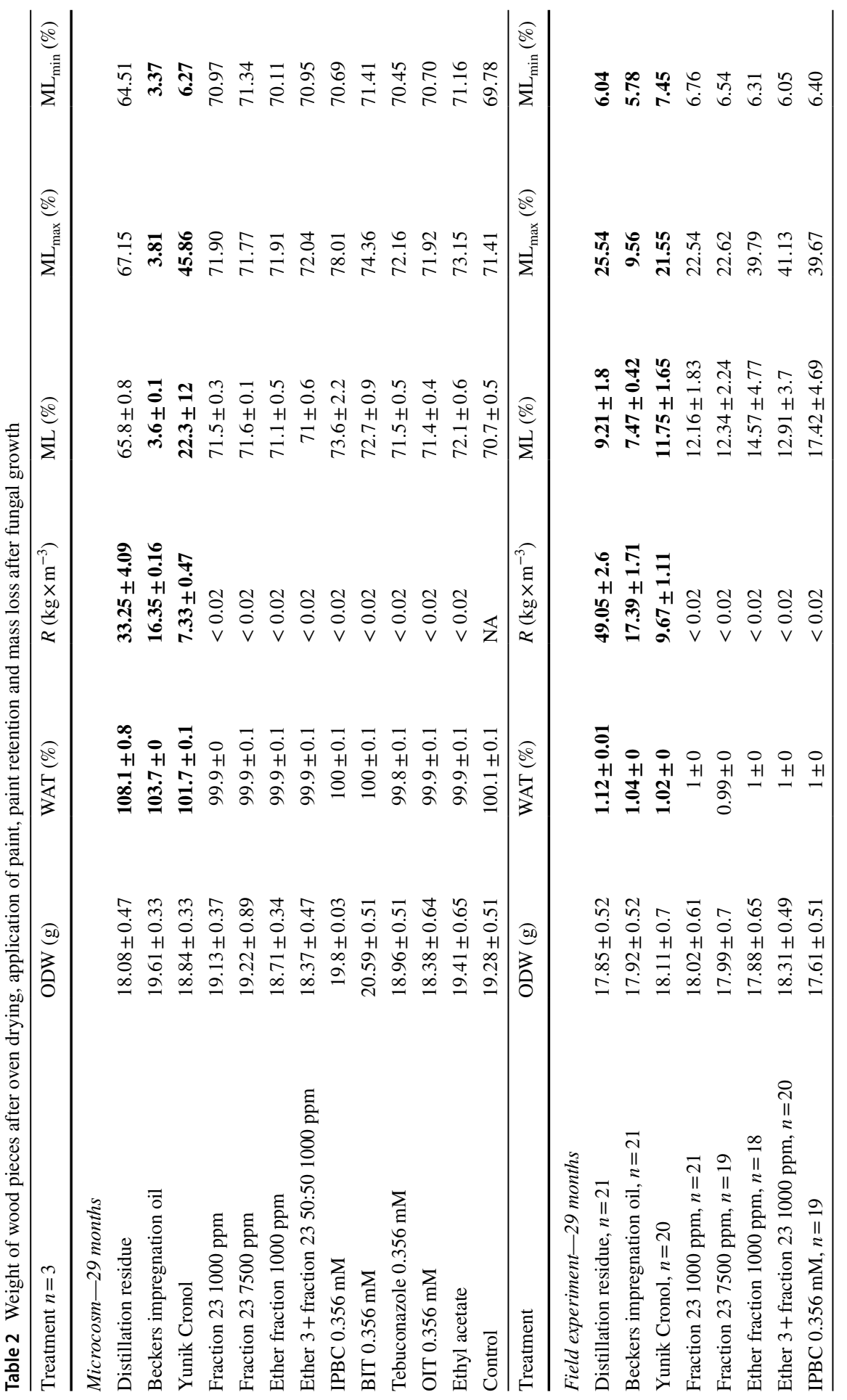




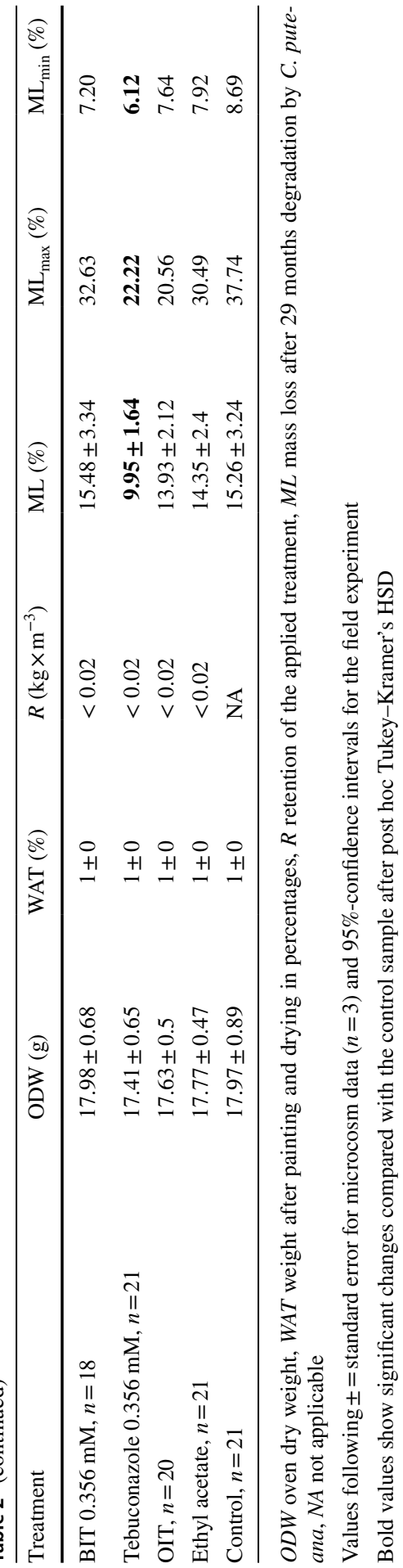


IPBC and propiconazole (not included in this study) supplied in Beckers impregnation oil are released and effective $C$. puteana fungicides at a distance. This result is consistent with data from EPA 738-R-97-003 that suggest IPBC to be very mobile to mobile $\left(K<2.64 \mathrm{~mL} \mathrm{~g}^{-1}\right)$ in mineral soils. Propiconazole on the other hand is considered a substance stable to aerobic soil metabolism and moderate to relatively mobile in soil according to EPA 738R-06-027. As this latter compound is not present in Yunik Cronol, it is highly likely that the observed antimycotic effect is caused by an increased concentration of the propiconazole in Beckers impregnation oil or by IPBC-propiconazole synergism.

A slight growth at the end grain of wood pieces treated with Yunik Cronol was observed at the end of the experiment (Fig. 2). No other treatment effects were observed. The mean coefficient of variance (CV) across all samples for mass loss data was determined as $4 \pm 2 \%$. Except for treatments that significantly inhibited wood degradation, wood mass loss at the end of the experiment reached its maximum at approximately $71 \%$ with typical brown-rot characteristics. Any treatment time lag was thus unnoticeable. The measured mass loss should be at the maximum degradation capacity that $C$. puteana can exhibit overall or perhaps with the time and resources supplied. Norway spruce stem wood contains $42.0 \pm 1.2 \%$ cellulose, $27.3 \pm 1.6 \%$ hemicelluloses, $27.4 \pm 0.7 \%$ lignin and $2.0 \pm 0.6 \%$ extractives. Furthermore, it is known that brown-rot fungi leave a chemically modified lignin (Goodell 2003). Reasonably, the remaining wood mass consists of this modified lignin with substantial degradation of the other biopolymers.

Additionally, the commercial products left a decidedly higher mass after treatment of the wood pieces, likely implying that a water excluding and protective layer remained. However, additive mass increase was most noticeable for the distillation residue with an average retention of $33.25 \mathrm{~kg} \mathrm{~m}^{-3}$ (8.1\% relative increase). This is probably due to its low volatility and high molecular weight resin (palmitic, pimaric, abietic, dehydroabietic, behenic, isopimaric) acid content (Lindmark-Henriksson 2003). Residue retention levels were, in relatively comparable surface/volume ratios, lower than those for linseed, rustikal and tung oils (Humar and Lesar 2013). This is to be expected as the present treatments were applied topically, while vacuum/pressure impregnation was used in the previous study, improving penetration depth. In comparison, industrial chromated copper arsenate preservative retention is effective

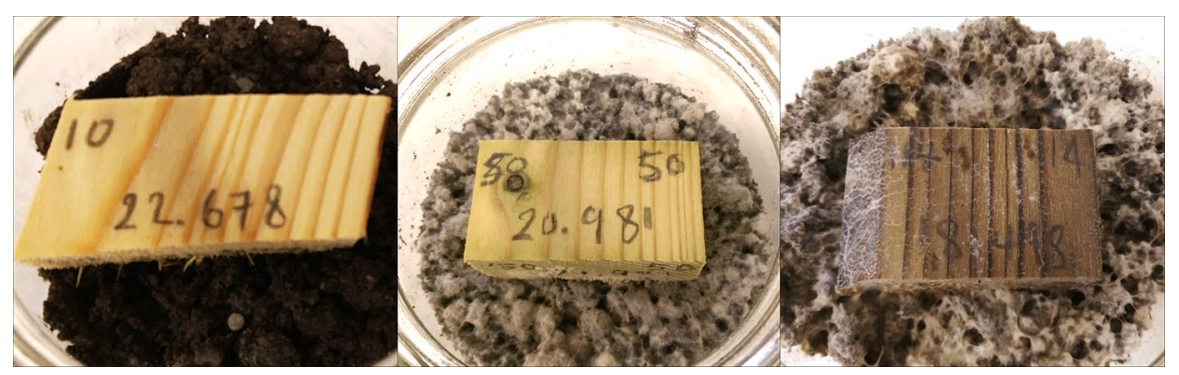

Fig. 2 Microcosm fungal growth after 29 months. Microcosm images from left to right: wood pieces treated with: Beckers impregnation oil, Yunik Cronol and distillation residue 
at approximately $2.0 \mathrm{~kg} \mathrm{~m}^{-3}$ (use class 3 ) and $10.2 \mathrm{~kg} \mathrm{~m}^{-3}$ (use class 4 ). However, given enough time and ample resources, the brown-rot fungus $C$. puteana was able to survive the applied resinous acids from the distillation residue. This finding suggests that shorter application intervals or complementary formulation may be necessary to maintain a long-term and adequate defence.

\section{Field study}

Prior to placing the wood pieces in the field, residuals of weight after painting and room temperature equilibration were examined. Three observations deviated from the rest with $\mathrm{z}$-score $=2.42,2.08$ and 2.66 for treatment with ether $3+$ fraction 23 , ethyl acetate and the control, respectively. Wood density, the presence of knots and other nonconformities may have caused these results but as the dry weight after painting and drying should belong to a normal distribution, and when, additionally, the aim is to have a uniform group before outdoor placement, these outliers from WAT residuals were removed before further data processing. In addition, ten samples were missing in the field at the end of the experiment, which resulted in a total of 260 wood pieces examined across thirteen treatments (Table 2).

Wood pieces were tested on-ground corresponding to EN use class 4, and as it is generally known that the naturally existing fungal community has a substantial effect on the decay, field trials were carried out at three different locations. Treatment considerably affected wood mass loss after 29 months $\left[F_{12,214}=21.73\right.$, $p \ll 0.05]$. Surprisingly, location had no impact $\left[F_{2,214}=0.1, p=0.82\right]$ and no evidence that treatment effect would depend on location was found [Treatment $\times$ Location: $F_{24,214}=1.07, p=0.45$ ]. This could indicate a homogeneous fungal community across locations or broad-spectrum fungal decay resistance of successful treatments. Thus, the categorical variable location was excluded, and treatment types were pooled prior to further calculations.

As expected, CV-values were markedly increased in the field experiment, with the minimum value recorded for Beckers impregnation oil (12.2\%) and the highest for treatment with ether fraction $3+$ fraction 23 (65.8\%). CV-value for the control samples was determined as $46.6 \%$ and a mean mass loss of $15.7 \%$ (Table 2). Even though these values were considerably higher than microcosm experiments, Beckers impregnation oil, distillation residue and tebuconazole still showed large and significant effect sizes (Cohen 1995) close to or above one (Fig. 3). Fraction 23 was determined as marginally significant as its confidence interval did not include 0 at a $90 \%$ confidence level. This result is encouraging when considering the low retention applied. On a per molar basis, tebuconazole at a concentration of approximately $110 \mathrm{ppm}$ is suggested as the most effective treatment, a result that is congruent with previous findings (Schultz and Nicholas 2002; Volkmer and Schwarze 2008). Furthermore, the amount of tebuconazole applied to each substrate could not be measured down to the nearest milligram, which demonstrates its high efficacy at low retention levels. A reason for the higher efficacy of tebuconazole than the carbamate IPBC is probably due to its higher affinity for wood (Kjellow et al. 2010). Its use, however, is limited by harmful effects on animals. In fact, most chemicals 


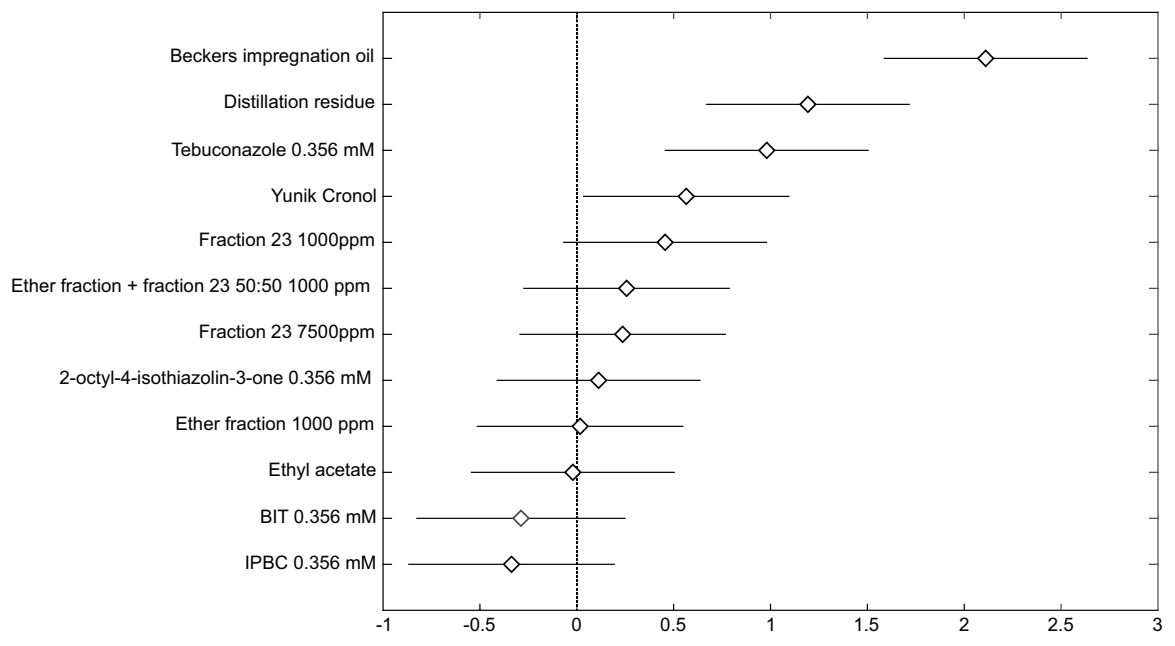

Fig. 3 Hedges' g of treatments by standardised effect sizes. Hedges' g standardised effect sizes of different treatments applied for 29 months in the field. Error bars show confidence intervals (95\%)

classified as wood preservatives are toxic to the environment and exhibit relatively inert biodegradation properties (Salminen et al. 2014). Replacing these hazardous compounds with environmentally degradable yet functional alternatives is a key target in the wood impregnation industry.

Herein, the residue from TMP-T distillation exhibited wood protection qualities that could not be statistically distinguished from a formulated commercial alternative supplemented with the carbamate IPBC and the triazole fungicide propiconazole. Efficacies of some constituents of the residue have shown that abietic acid exhibited an effect on white-rot fungi Trametes versicolor, while both abietic and dehydroabietic acid affected growth of Irpex lacteus (Eberhardt et al. 1994). Furthermore, Kusumoto et al. (2014) showed that abietic and dehydroabietic acids displayed the highest antifungal activities compared with some monoterpenes and monoterpenoids. TMP-T residue may therefore be an interesting alternative to triazole derivatives and monoterpenes.

The current study included an evaluation of potential growth inhibitory effects from different TMP-T fractions and with strong evidence that such effects are present when tested against a wide range of fungal species grown on agar. In lieu of crude oils, an increase in antifungal efficacy by fractional distillation was observed. This strategy may well work to increase antifungal efficacy on other types of pulp and paper by-products, such as tall oil (Koski 2008). Experiments on wood substrate show that additional studies are needed on how to formulate and apply these compounds to ensure long-term effects. Interestingly, the most promising fraction from antifungal assays on agar-plates, TMP-T fraction 23 , showed moderately effective wood protective qualities at the low retention applied $\left(<0.02 \mathrm{~kg} \mathrm{~m}^{-3}\right)$, even at severe wetting conditions comparable to use class 4 . Furthermore, TMP-T residue outperformed, on average, a commercial product. Provided that a suitable formulation for 
their application can be found, the identified fractions may offer environmentally friendly wood protection based on a renewable feedstock.

\section{Future perspectives}

Natural compounds continue to draw attention as non-toxic and eco-friendly alternatives to more toxic treatments using synthetic and heavy metal wood preservatives. Nevertheless, due to their presence in a natural cycle, phytochemicals frequently present in woody material are likely guaranteed to have an antagonistic organism capable of their biodegradation. Natural product treatment with TMP-T distillation residue may require shorter treatment intervals for up-keeping a high biodeterioration resistance in outdoor wood. This potentially work-intensive drawback may be ameliorated with impregnation techniques and optimal formulations. As the formulation of active wood preservative components, as well as their application to wood pieces, has a significant impact on their performance (Freeman 2008), a potential remedy may be to add, for example, a drying film that successfully retains active compounds for extended periods and further reduces water uptake (Humar and Lesar 2013). Inspired by the utilisation of highly active antiretroviral therapy in HIV treatments and previously suggested by Schultz and Nicholas (2002), a multi-target strategy could additionally be employed to increase the effectiveness of treatments while keeping a low individual concentration of each treatment. For example, combine: lignans, flavonoids and diterpenes to stave off reactive oxygen species and modulate fungal membrane fluidity; metal chelators such as troponoids to inhibit the Fenton reaction and metal-requiring enzymes laccases, tyrosinases and lipoxygenases; poacic acid to hamper $\beta$-1,3-glucan synthesis in the outer hyphal membrane (Piotrowski et al. 2015); alcohol terpenoids from TMP-T to partition in the outer cellular membrane and inhibit $\mathrm{H}(+)$-ATPase that ultimately lead to intracellular acidification and cell death (Ahmad et al. 2010; Valette et al. 2017). Such natural protection schemes could potentially achieve wood decay resistance on a broad scale and may therefore be an interesting alternative as a versatile and multifunctional wood preservative. Hence, formulation with natural compounds may replace synthetic and heavy metal wood preservatives and should attract the attention of the wood preservation community. Herein, it is suggested that the readily available by-product thermomechanical pulp turpentine may be applicable as a component in analogous formulations, but further studies with standard industrial impregnation methods are required to accurately establish toxicity levels, moisture performance (Meyer-Veltrup et al. 2017), evaluate long-term efficacy, for example EN 252 (2015), and ultimately assess the practical use of high-boiling TMP-turpentine fractions at the industrial scale.

\section{Conclusion}

In conclusion, TMP-turpentine fractions with higher-boiling constituents revealed significantly enhanced antifungal performance in vitro and in vivo. Taken together, the present results show that fractional distillation of the industrially 
abundant by-product TMP-turpentine can be used to inhibit wood biodeterioration and increase the service life of wood-based products.

Acknowledgements Open access funding provided by Mid Sweden University. This project was made possible with the funding from the European Regional Development Fund (Mål 2) and the County Administrative Board of Västernorrland. The authors are thankful to Oddmund Björkås at SCA Ortviken, Sweden, for providing turpentine, and to Saba Hagos and Mikael Gudrunsson for laboratory assistance. We also thank Håvard Kauserud for providing strains of S. lacrymans and Dr. Jennie Sandström for tree ring width measurements.

\section{Compliance with ethical standards}

Conflict of interest The authors declare that they have no conflict of interest.

Open Access This article is licensed under a Creative Commons Attribution 4.0 International License, which permits use, sharing, adaptation, distribution and reproduction in any medium or format, as long as you give appropriate credit to the original author(s) and the source, provide a link to the Creative Commons licence, and indicate if changes were made. The images or other third party material in this article are included in the article's Creative Commons licence, unless indicated otherwise in a credit line to the material. If material is not included in the article's Creative Commons licence and your intended use is not permitted by statutory regulation or exceeds the permitted use, you will need to obtain permission directly from the copyright holder. To view a copy of this licence, visit http://creativecommons.org/licen ses/by/4.0/.

\section{References}

Ahmad A, Khan A, Yousuf S, Khan LA, Manzoor N (2010) Proton translocating ATPase mediated fungicidal activity of eugenol and thymol. Fitoterapia 81:1157-1162. https://doi.org/10.1016/j.fitot e.2010.07.020

Akgül A, Kivanç M (1989) Sensitivity of four foodborne moulds to essential oils from Turkish spices, herbs and citrus peel. J Sci Food Agric 47:129-132

Arnerup J, Lind M, Olson K, Stenlid J, Elfstrand M, Näsholm T (2011) The pathogenic white-rot fungus Heterobasidion parviporum triggers non-specific defence responses in the bark of Norway spruce. Tree Physiol 31:1262-1272. https://doi.org/10.1093/treephys/tpr113

Asiegbu FO, Adomas A, Stenlid J (2005) Conifer root and butt rot caused by Heterobasidion annosum (Fr.) Bref. s.1. Mol Plant Pathol 6:395-409. https://doi.org/10.1111/j.1364-3703.2005.00295.x

Bakkali F, Averbeck S, Averbeck D, Idaomar M (2008) Biological effects of essential oils-a review. Food Chem Toxicol 46:446-475. https://doi.org/10.1016/j.fct.2007.09.106

Belletti N, Ndagijimana M, Sisto C, Guerzoni ME, Lanciotti R, Gardini F (2004) Evaluation of the antimicrobial activity of citrus essences on Saccharomyces cerevisiae. J Agric Food Chem 52:69326938. https://doi.org/10.1021/jf049444v

Boddy L, Frankland JC, West Pv (2008) Ecology of saprotrophic basidiomycetes. In: British mycological society symposia series, vol 28. Elsevier, London

Boulogne I, Loranger-Merciris G, Ozier-Lafontaine H, Desfontaines L, Petit P (2012) Insecticidal and antifungal chemicals produced by plants: a review. Environ Chem Lett 10:325-347

Brischke C, Melcher E (2015) Performance of wax-impregnated timber out of ground contact: results from long-term field testing. Wood Sci Technol 49:189-204. https://doi.org/10.1007/s0022 6-014-0692-6

Burt S (2004) Essential oils: their antibacterial properties and potential applications in foods-a review. Int J Food Microbiol 94:223-253. https://doi.org/10.1016/j.ijfoodmicro.2004.03.022

Chong J, Poutaraud A, Hugueney P (2009) Metabolism and roles of stilbenes in plants. Plant Sci 177:143-155. https://doi.org/10.1016/j.plantsci.2009.05.012

Cohen J (1995) Statistical power analysis for the behavioral sciences. Erlbaum, Hillsdale 
Eberhardt TL, Young RA, Han JS, Micales JA (1994) Decay resistance in conifer seed cones: role of resin acids as inhibitors of decomposition by white-rot fungi. Holzforschung 48:278-284. https:// doi.org/10.1515/hfsg.1994.48.4.278

EN 335 (2013) Durability of wood and wood-based products-use classes: definitions, application to solid wood and wood-based products. CEN (European Committee for Standardization) Brussels

EN 252 (2015) EN 252, 2014. Field test method for determining the relative protective effectiveness of a wood preservative in ground contact. CEN (European Committee for Standardization) Brussels

Freeman MH (2008) Wood preservative formulation development and systems: organic- and inorganicbased systems. In: Development of commercial wood preservatives, American Chemical Society, Washington, vol 982, pp 408-426. https://doi.org/10.1021/bk-2008-0982.ch024

Goodell B (2003) Brown-rot fungal degradation of wood: our evolving view. ACS Symp Ser 845:97-118. https://doi.org/10.1021/bk-2003-0845.ch006

Groth AB (1958) Investigations on Swedish turpentine. Svensk Papperstidning 6:311-321

Hedenström E, Fagerlund Edfeldt A, Edman M, Jonsson BG (2016) Resveratrol, piceatannol, and isorhapontigenin from Norway spruce (Picea abies) debarking wastewater as inhibitors on the growth of nine species of wood-decaying fungi. Wood Sci Technol 50:617-629. https://doi.org/10.1007/s0022 6-016-0814-4

Humar M, Lesar B (2013) Efficacy of linseed- and tung-oil-treated wood against wood-decay fungi and water uptake. Int Biodeterior Biodegrad 85:223-227. https://doi.org/10.1016/j.ibiod .2013 .07 .011

Hyvönen A, Piltonen P, Niinimäki J (2006) Tall oil/water-emulsions as water repellents for Scots pine sapwood. Holz Roh Werkst 64:68-73. https://doi.org/10.1007/s00107-005-0040-5

Inouye S, Watanabe M, Nishiyama Y, Takeo K, Akao M, Yamaguchi H (1998) Antisporulating and respiration-inhibitory effects of essential oils on filamentous fungi. Mycoses 41:9-10

Inui T, Wang Y, Pro SM, Franzblau SG, Pauli GF (2012) Unbiased evaluation of bioactive secondary metabolites in complex matrices. Fitoterapia 83:1218-1225. https://doi.org/10.1016/j.fitot e.2012.06.012

Izumi E, Ueda-Nakamura T, Veiga VF Jr, Pinto AC, Nakamura CV (2012) Terpenes from Copaifera demonstrated in vitro antiparasitic and synergic activity. J Med Chem 55:2994-3001

Kamo M, Yokomizo H (2015) Explanation of non-additive effects in mixtures of similar mode of action chemicals. Toxicology 335:20-26. https://doi.org/10.1016/j.tox.2015.06.008

Kirker GT, Blodgett AB, Arango RA, Lebow PK, Clausen CA (2013) The role of extractives in naturally durable wood species. Int Biodeterior Biodegrad 82:53-58. https://doi.org/10.1016/j.ibiod .2013 .03 .007

Kjellow AW, Henriksen O, Sørensen JC, Johannsen M, Felby C (2010) Partitioning of organic biocides between wood and supercritical carbon dioxide. J Supercrit Fluids 52:1-5. https://doi. org/10.1016/j.supflu.2009.12.005

Kleist G, Schmitt U (2001) Characterisation of a soft rot-like decay pattern caused by Coniophora puteana (Schum.) Karst. in Sapelli Wood (Entandrophragma cylindricum Sprague). Holzforschung 55:6. https://doi.org/10.1515/hf.2001.093

Koski A (2008) Applicability of crude tall oil for wood protection. Doctoral thesis, University of Oulu

Kramer R, Abraham WR (2012) Volatile sesquiterpenes from fungi: what are they good for? Phytochem Rev 11:15-37. https://doi.org/10.1007/s11101-011-9216-2

Kuć J, Rush JS (1985) Phytoalexins. Arch Biochem Biophys 236:455-472. https://doi. org/10.1016/0003-9861(85)90648-4

Kusumoto N, Zhao T, Swedjemark G, Ashitani T, Takahashi K, Borg-Karlson AK (2014) Antifungal properties of terpenoids in Picea abies against Heterobasidion parviporum. Forest Pathol 44:353-361. https://doi.org/10.1111/efp.12106

Lindmark-Henriksson M (2003) Biotransformations of turpentine constituents: oxygenation and esterification. Doctoral thesis, Royal Institute of Technology (KTH), Stockholm

Liu M, Zhong H, Ma E, Liu R (2018) Resistance to fungal decay of paraffin wax emulsion/copper azole compound system treated wood. Int Biodeterior Biodegrad 129:61-66. https://doi. org/10.1016/j.ibiod.2018.01.005

Ljunggren J, Bylund D, Jonsson BG, Edman M, Hedenström E (2020) Antifungal efficiency of individual compounds and evaluation of non-linear effects by recombining fractionated turpentine. Microchem J. https://doi.org/10.1016/j.microc.2019.104325 
Lopez-Reyes JG, Spadaro D, Prelle A, Garibaldi A, Gullino ML (2013) Efficacy of plant essential oils on postharvest control of rots caused by fungi on different stone fruits in vivo. J Food Prot 76:631-639. https://doi.org/10.4315/0362-028X.JFP-12-342

Maree J, Kamatou G, Gibbons S, Viljoen A, Van Vuuren S (2014) The application of GC-MS combined with chemometrics for the identification of antimicrobial compounds from selected commercial essential oils. Chemometr Intell Lab Syst 130:172-181. https://doi.org/10.1016/j.chemo lab.2013.11.004

Martin D, Tholl D, Gershenzon J, Bohlmann J (2002) Methyl jasmonate induces traumatic resin ducts, terpenoid resin biosynthesis, and terpenoid accumulation in developing xylem of norway spruce stems. Plant Physiol 129:1003-1018

Martínez A, Rojas N, García L, González F, Domínguez M, Catalán A (2014) In vitro activity of terpenes against Candida albicans and ultrastructural alterations. Oral Surg Oral Med Oral Pathol Oral Radiol 118:553-559. https://doi.org/10.1016/j.oooo.2014.07.009

Medeiros FCMd, Gouveia FN, Bizzo HR, Vieira RF, Del Menezzi CHS (2016) Fungicidal activity of essential oils from Brazilian Cerrado species against wood decay fungi. Int Biodeterior Biode$\operatorname{grad} 114: 87-93$. https://doi.org/10.1016/j.ibiod.2016.06.003

Meyer-Veltrup L, Brischke C, Alfredsen G et al (2017) The combined effect of wetting ability and durability on outdoor performance of wood: development and verification of a new prediction approach. Wood Sci Technol 51:615-637. https://doi.org/10.1007/s00226-017-0893-x

Miladinovic DL, Ilic BS, Mihajilov-Krstev TM, Nikolic ND, Miladinovic LC, Cvetkovic OG (2012) Investigation of the chemical composition-antibacterial activity relationship of essential oils by chemometric methods. Anal Bioanal Chem Analyt Bioanalyt Chem 403:1007-1018

Palmer J (1971) Techniques and procedures for culturing ectomycorrhizal fungi. In: Proceedings of the 1st North American conference on mycorrhizae, p 132-144

Piotrowski JS, Okada H, Lu F et al (2015) Plant-derived antifungal agent poacic acid targets beta1,3-glucan. Proc Natl Acad Sci USA 112:E1490-E1497. https://doi.org/10.1073/pnas.14104 00112

Råberg U, Hafrén J (2008) Biodegradation and appearance of plastic treated solid wood. Int Biodeterior Biodegrad 62:210-213. https://doi.org/10.1016/j.ibiod.2007.12.006

Rivas da Silva AC, Lopes PM, Barros de Azevedo MM, Costa DC, Alviano CS, Alviano DS (2012) Biological activities of $\alpha$-pinene and $\beta$-pinene enantiomers. Molecules 17:6305-6316. https:// doi.org/10.3390/molecules17066305

Ryvarden L, Melo I (2014) Poroid fungi of Europe. Synopsis fungorum, vol 31. Fungiflora, Oslo

Salem MZM, Zidan YE, Mansour MMA, El Hadidi NMN, Abo Elgat WAA (2016) Antifungal activities of two essential oils used in the treatment of three commercial woods deteriorated by five common mold fungi. Int Biodeterior Biodegrad 106:88-96. https://doi.org/10.1016/j.ibiod .2015 .10 .010

Salminen E, Valo R, Korhonen M, Jernlås R (2014) Wood preservation with chemicals: best available techniques (BAT). TemaNord, vol 2014, p 550. Nordisk Ministerråd, Copenhagen. https://doi. org/10.6027/tn2014-550

Scardavi A (1966) Synergism among fungicides. Annu Rev Phytopathol 4:335-346

Schmidt O (2006) Wood and tree fungi: biology, damage, protection, and use. Springer, Berlin. https ://doi.org/10.1007/3-540-32139-X

Schmidt O, Moreth U (1995) Detection and differentiation of poria indoor brown-rot fungi by polyacrylamide gel electrophoresis. Holzforschung 49:11-14. https://doi.org/10.1515/ hfsg.1995.49.1.11

Schultz TP, Nicholas DD (2000) Naturally durable heartwood: evidence for a proposed dual defensive function of the extractives. Phytochemistry 54:47-52. https://doi.org/10.1016/S0031 $-9422(99) 00622-6$

Schultz TP, Nicholas DD (2002) Development of environmentally-benign wood preservatives based on the combination of organic biocides with antioxidants and metal chelators. Phytochemistry 61:555-560. https://doi.org/10.1016/S0031-9422(02)00267-4

Sen S (2001) Determination of wood preservative activities of plant phenolics. Doctoral thesis, Zonguldak Karaelmas University. Graduate school of natural and applied sciences

Shukla R, Singh P, Prakash B, Dubey NK (2012) Antifungal, aflatoxin inhibition and antioxidant activity of Callistemon lanceolatus (Sm.) Sweet essential oil and its major component 1,8-cineole against fungal isolates from chickpea seeds. Food Control 25:27-33. https://doi. org/10.1016/j.foodcont.2011.10.010 
Smith RL, Cohen SM, Doull J et al (2005) A procedure for the safety evaluation of natural flavor complexes used as ingredients in food: essential oils. Food Chem Toxicol 43:345-363. https://doi. org/10.1016/j.fct.2004.11.007

Speer JH (2010) Fundamentals of tree-ring research. University of Arizona Press, Tucson

Stalpers J (1978) Identification of wood-inhabiting Aphyllophorales in pure culture. In: Studies in mycology 16. Centraalbureau voor Schimmelcultures, Baarn

Stokland JN (2012) Host-tree associations. In: Stokland JN, Siitonen J, Jonsson BG (eds) Biodiversity in dead wood. Cambridge University Press, Cambridge, pp 82-109. https://doi.org/10.1017/ cbo9781139025843.006

Tallarida RJ (2001) Drug synergism: its detection and applications. J Pharmacol Exp Ther 298:865-872

Valette N, Perrot T, Sormani R, Gelhaye E, Morel-Rouhier M (2017) Antifungal activities of wood extractives. Fungal Biol Rev 31:113-123. https://doi.org/10.1016/j.fbr.2017.01.002

Van de Vel E, Sampers I, Raes K (2019) A review on influencing factors on the minimum inhibitory concentration of essential oils. Crit Rev Food Sci Nutr 59:357-378. https://doi. org/10.1080/10408398.2017.1371112

Volkmer T, Schwarze FWMR (2008) Diffusion behavior of IPBC in water based coatings on wooden facades. Holz Roh Werkst 66:181-189. https://doi.org/10.1007/s00107-008-0240-x

Wang SY, Chen PF, Chang ST (2005) Antifungal activities of essential oils and their constituents from indigenous cinnamon (Cinnamomum osmophloeum) leaves against wood decay fungi. Biores Technol 96:813-818. https://doi.org/10.1016/j.biortech.2004.07.010

Zhang Z, Yang T, Mi N, Wang Y, Li G, Wang L, Xie Y (2016) Antifungal activity of monoterpenes against wood white-rot fungi. Int Biodeterior Biodegrad 106:157-160. https://doi.org/10.1016/j. ibiod.2015.10.018

Publisher's Note Springer Nature remains neutral with regard to jurisdictional claims in published maps and institutional affiliations.

\section{Affiliations}

\section{Joel Ljunggren ${ }^{1} \cdot$ Mattias Edman $^{2} \cdot$ Bengt Gunnar Jonsson $^{2} \cdot$ Dan Bylund $^{2}$. Erik Hedenström ${ }^{1}$}

Joel Ljunggren

joel.ljunggren@miun.se

Mattias Edman

mattias.edman@miun.se

Bengt Gunnar Jonsson

bengt-gunnar.jonsson@miun.se

Dan Bylund

dan.bylund@miun.se

Erik Hedenström

erik.hedenstrom@miun.se

1 Department of Chemical Engineering, Mid Sweden University, 85170 Sundsvall, Sweden

2 Department of Natural Sciences, Mid Sweden University, 85170 Sundsvall, Sweden 